\title{
The Impacts of Supply and Demand Analysis on the Price of the Real Estate Market
}

\author{
Haiying $\mathrm{Ma}^{1, \mathrm{a}^{*}}$ and Jiangqiao $\mathrm{Li}^{2, \mathrm{~b}}$ \\ ${ }^{1,2}$ School of Economics, Northwest University for Nationalities, Lanzhou (730124), P.R. China \\ axmahaiying8888@163.com, ${ }^{\mathrm{b}} 798110670 @ q q . c o m$
}

Keywords: The real estate market; Supply and demand; Housing price

\begin{abstract}
The Initial estimation model and on the basis of this article to residual autocorrelation and heteroscedasticity testing for many times, finally determine the regression equation. The equation reflects the dynamic relationship between the real estate market supply and demand and the price of real estate. The study have shown that demand is positive effect on the real estate market, supply is negative effect on the real estate market, and the influence degree of the demand for real estate should be greater than the impact of supply. According to the above from the perspective of the real estate market supply and demand to analyze its effects on prices.
\end{abstract}

\section{Introduction}

The real estate industry is the basic industry of national economy, and is the leading industry in the national economy, and the national economic situation, economic policy and industrial policy has a strong correlation, it has a series of economic characteristics, including periodicity, sensitivity, scarcity and non-separability. The development of the real estate market should follow the economic law, the law of supply and demand is the main decision rule of real estate prices, all other factors impact on real estate prices, either by affecting the supply of real estate, either by affecting the demand for real estate, either through at the same time, the impact of real estate supply and demand to achieve. Therefore, it is very important to grasp the relationship between supply and demand of real estate and real estate price. The following mainly from the real estate supply and demand analysis of two aspects. Supply side of real estate. Real estate supply refers to the number of real estate developers and owners who are willing and able to sell at a given price for a specified period of time. Development capacity is undoubtedly the main factor of supply, because the real estate industry is a typical capital intensive industry, its development capacity is affected by the cost of development, the development of profits and other factors. The rise in the cost of development at relatively stable market prices will reduce the profits of development, thereby reducing the supply of real estate; on the contrary, it will increase the supply of real estate. Real estate demand side. Real estate demand refers to the consumer at a specific time, according to the specific price is willing to have the ability to purchase the number of the real estate, the main factor is the purchasing power of consumers.

Real estate market prices, mainly in the real estate market demand and market supply tends to balance the price. In the current economic condition, the supply and demand at the same time appear artificially enlarged, the double growth to the development of a relatively high stage, the final result is reflected in the price, in which supply and demand are relatively high peak condition, its price is bound to at a higher position. This paper discuss the supply and demand of the current real estate market, then presents an impirical analysis of price changing of real estate.Finally the paper make the conclution.

\section{The Supply and Demand of the Current Real Estate Market}

Supply of the Real Estate Market. First of all, from the perspective of the real estate market supply, the supply of real estate is the supply of land for real estate development. Therefore, the development 
of real estate and land system is closely linked. Our country's land belongs to the state ownership, So the land by the national government monopoly control, The government is the only owner of land.

Land Supply. The urban land supply for the city's real estate market supply is the city's land supply, Urban land by the city government to exercise the ownership of the state land, So, urban land indirectly under the control of the city government, in recent years, the city land is mainly used for construction of ordinary housing, with a luxurious residence, industrial and commercial land use, etc.. In addition, it speeding up of urbanization, this leads to crowding in land, all kinds of enterprises competing for this limited land resources, from this aspect, the land in the city is in short supply.

Rural land supply is mainly used for residential land and agricultural land, Because of the rural population is now moving to the cities, gradually toward the path of urbanization, a lot of rural housing land is vacant, from this point of view, The supply of rural land has the certain control of flexibility.

Capital Supply. With the improvement of living standards, More and more people hold the vacancy of cash balances, bank deposits in the monetary amount is also more and more, real estate development enterprises can from the bank or private capital owners focus people idle fund.

Employees Supply. Real estate market supply indicators can be measured in real estate development investment, real estate development enterprises construction area, the real estate development land acquisition area, etc. Real estate development investment is at a certain reporting period for housing construction projects, land development project investment and public welfare construction and land purchase expense, etc. table 1 is the investment supply index from 2008 to 2014 of the real estate market in china,from 2008 to 2014,china's real estate development and investment are in the stage of rapid growth, in 2011, china's real estate market regulation policy, the landlord estate development investment reduction.

Table 1 the real estate market supply situation in national level in 2008-2014 Hundred million Yuan and square meter

\begin{tabular}{c|c|c|c}
\hline year & national investment & construction area & land purchase area \\
\hline 2008 & 30580 & 27.4 & 3.7 \\
2009 & 35232 & 31.96 & 3.19 \\
2010 & 48267 & 40.44 & 4.1 \\
2011 & 61740 & 50.8 & 4.1 \\
2012 & 71804 & 57.34 & 3.6 \\
2013 & 86013 & 66.56 & 3.9 \\
2014 & 95036 & 72.65 & 3.3 \\
\hline
\end{tabular}

\section{The Demand of Real Estate Market.}

Residential Demand. Both urban and rural residents have living needs.. Especially residential of some economically developed city. It demand increased, the city is absorbed into the various kind of talent, There is a floating population to local population in terms of residential demand coordination and balance.

Investment Demand. At present, the stock market downturn, The rapid growth of the money supply, many city residents have very large deposits, but also affected the current deposits interest rate. These people think rather than keep the deposit in the bank, it is better to invest to business or real estate industries investment channels, etc., At present, the real estate prices have been in a relatively high state, which is even more increase the residents who have a lot of deposits the investment confidence.

Psychological Needs. At present most residents psychological preferences changed for cash deposits, Along with the rising prices, The emergence of inflation, People want their rather than cash, bank deposits, people hope to have fixed assets and it is the value of fixed asset, As house prices rising. most people put the target in the real estate market. For example, the purchase of commercial 
housing and other acts, this behavior is a kind of psychological needs of people, more and more people into the real estate market, people have a herd mentality, this mentality will inspire people to the real estate market to increase investment.

Speculative Demand. The emergence of the so-called room worm, people is speculative on the real estate market is the most powerful proof. In reality, in collusion with some real estate developers and intermediaries, to bid up property prices, For the measurement market demand of the real estate indicators are the national commodity sales area, the amount of sales etc. Table 2 is made from 2008 to 2012, china's commodity sales area, we can see that the demand for real estate market is still relatively strong.

Table 2 the total sales of real estate in term of square meter in China 2008-2014

\begin{tabular}{c|c|c|c|c|c|c|c}
\hline Year & 2008 & 2009 & 2010 & 2011 & 2012 & 2013 & 2014 \\
sales & 62089 & 93713 & 104349 & 109946 & 111304 & 130551 & 120649 \\
\hline
\end{tabular}

\section{Empirical Analysis}

The Real Estate Price Index. Indices of the real estate price changes, known as the real estate price index, this is a relative number, the main performance of the real estate price changes, the percentage is reflected in the form of price changes in different periods, The selection of different countries for the real estate price index is not the same in our country, with the housing sales price index, the State Housing boom index to reflect the real estate price in china.

Housing Sales Price Index. Housing sales price index is aimed at a certain period of time, the real estate sales price movements, it is a relative number, but also to show the percentage of price in different periods of change, Here, the main real estate, including commercial housing, public housing and private housing major categories of housing. This method can be used to reflect the changes in the magnitude of changes in the relationship between supply and demand and the corresponding cost fluctuations, Another important point is that the index excluding the quality of housing, building structure, location sales structure and other factors.

Housing Rental Price Index. Housing rental price index refers to the changes in housing rental prices during a given period, which is a relative number, the rental price refers to the housing rental housing to pay the lessor, this way through the housing lease, the Lessor will be transferred to the use of the right to use the housing, Ownership, however, does not shift, it includes five parts: residential leasing, office space rental, commercial housing lease, factory warehouse rental and hotel room rental.

The Land Exchange Price Index. Land transaction price index refers to the real estate developers to purchase land for the development of land use rights and the actual payment of the price changes, which is reflected as a relative number, in the real estate developers to pay the price does not include the subsequent development costs, taxes, fees and fees. Land transaction price index reflects the changes in the price of land use rights in a certain period of time.

Real Estate Climate Index. State housing boom index , also known as the national housing index, It is short for the national real estate development industry comprehensive confidence. This is the National Bureau of statistics in 1997 to develop and set up a set of real estate development in the comprehensive quantitative index system, the index system is composed of 8 classification index of the composite index, The index selection of the basic indicators of investment in real estate development, including real estate investment, capital, size, sales and other indicators, china's housing boom index in 2000 as the base year, set the benchmark year growth level is 100, and the range of the index is provided, under normal circumstances, the most appropriate level is the index value in 95 to 105 points, the lower level is the index in the range below 95, The high level is the index range of more than 105 .

Model Building. Select the national real estate development investment as the real estate market supply indicators, the choice of the national commercial housing sales amount as the real estate 
market demand indicators, select the national housing boom index as the real estate price index, Select data form February 2011 to July 2015.

Model design: AS: investment in real estate development, AD: commercial housing sales amount, P: national housing boom index.

The choice of this paper is the first monthly data, seasonally adjusted by X12 method, secondly, on a seasonally adjusted AD, AS, P logarithmic, were recorded as LAD, LAS, LP. finally in the model for testing the stationarity of the variables, using the ADF method, the test results show that, at the 5\% significance level LAD, LAS and LP have all passed the test, as a stationary variable, direct modeling. The purpose of this paper is to investigate effects of Los Angeles real estate supply and demand on the real estate prices, from the macroeconomic theory, supply and demand lag impact on prices; from the perceptive of econometrics to explain the variables to explain the influence can not be completed in a short period of time, time delay usually exists in this process ,however, the distributed lag model length is difficult to determine, and if large lag and loss from the mountain, and some lag explanatory variables coefficient can not be tested, the above two cases, this paper set up a wooden stage explanatory variables and explanatory variables lag period of wood, a regression model of explanatory variables, lagged explanatory variables can be considered as a result of lag to explain your variables, so it can fully explain the variables on the explanatory variables an analysis of the influence, the model is as follows:

$$
L P_{t}=\beta_{0}+\beta_{1} \times L P_{t-1}+\beta_{2} \times L A S_{t}+\beta_{3} \times L A D_{t}+e_{t}
$$

The preliminary results of the model are as follows

$$
\begin{aligned}
& L P_{t}=-0.077064+0.9954 \times L P_{t-1}-0.02361 \times L A S_{t}+0.035506 \times L A D_{t}+e_{t} \\
& \text { (42.56617) (-4.432456) } \\
& \text { (8.356753) }
\end{aligned}
$$

The results of regression equation (1) show that the coefficients of all variables are tested at the 5\% significance level, but the residual have autocorrelation and heterscedasticit. After repeated attempts, the AR(4) model is used to correct the regression equation(1).

$$
\begin{aligned}
e_{t}= & 2.371762 \times e_{t-1}-2.54530 e_{t-2}+1.212481 \times e_{t-3}-0.390030 e_{t-4}+\varepsilon_{t} \\
& (14.15288)(-6.669715) \quad(3.726915)
\end{aligned}
$$

The results of regression equation (2) show that the residual coefficients of the equation (1) in the 1-4 period of lag are tested under the 5\% significance level, and the regression equation. The AC value, PAC value, $Q$ value of statistics that equation (2) there is no residual sequence autocorrelation, equation (1) can be estimated.

$$
\begin{aligned}
& y=L P_{t}-2.371762 L P_{t-1}+2.545305 \times L P_{t-2}-1.212481 \times L P_{t-3}+0.390030 \times L P_{t-4} \\
& z=L P_{t-1}-2.371762 L P_{t-2}+2.545305 \times L P_{t-3}-1.212481 \times L P_{t-4}+0.390030 \times L P_{t-5} \\
& x_{1}=L A S_{t}-2.371762 L A S_{t-1}+2.545305 \times L A S_{t-2}-1.212481 \times L A S_{t-3}+0.390030 \times L A S_{t-4} \\
& x_{2}=L A D_{t}-2.371762 L A D_{t-1}+2.545305 \times L A D_{t-2}-1.212481 \times L A S_{t-3}+0.390030 \times L A D_{t-4}
\end{aligned}
$$

The regression equation is as follows:

$$
\hat{y}=0.00102+0.969605 \times z-0.025351 \times x_{1}+0.037783 \times x_{2}
$$

The residuals of the equation are tested by autocorrelation and heteroscedasticiity. AC value, PAC value, Q statistic and White test show that the equation (3) does not have autocorrelation and heteroscedasticity, so the model can be reduced.

$$
L P_{t}=0.007651+0.969605 \times L P_{t-1}-0.025351 \times L A S_{t}+0.037783 \times L A D_{t}+\xi_{t}
$$

The influence of supply for housing prices is negative effect, The influence of the demand for housing is positive effect. the supply coefficient is less than the coefficient of demand, so that the cumulative effect of the previous lag period is positive, causing prices to rise, the regulation of housing prices is mainly to regulate the demand of the real estate market. 


\section{Conclusion}

From the analysis of the real estate supply and demand can be seen, due to the growing demand for the housing prices continue to rise, in order to fundamentally curb real estate prices, must be from the two aspects of supply and demand to control the estate price. Increasing the construction of affordable housing to protect the basic housing needs of residents, To meet the basic housing needs of residents in order to fundamentally alleviate the contradiction between supply and demand in the real estate market, increase investment in affordable housing construction. adjusting the people's expectations for the real estate market, curb speculative demand, Narrowing the gap between urban and rural residents income, reduce the high income groups on the real estate market expectations, which can ease some of the individual speculative demand. Adjusting the supply structure of commercial housing and affordable housing, To balance the supply of commercial housing and affordable housing, local governments can not only in order to achieve the economic benefits of the region and the construction of commercial housing and affordable housing supply.

\section{References}

[1] Yongzhong Wang, the real estate market supply and demand and the impact on the price, Modern Management. 8(20078)32-40.

[2] Zheng Ma, analyze the reasons of china's real estate price from two aspects of supply and demand, Commercial Economy. 9(2008)49-53.

[3] Tiemei Gao, econometric analysis and modeling method of E-view application and example, Tsinghua University Press, 2009.

[4] Lianguang Li, A decision model of two aspects of supply and demand of housing prices, Journal of North Central University. 3(2009)74-81.

[5] Juan Liu, a long-term mechanism on the regulation from the real estate market supply and demand, Modern Economic Information,15(2010)121-139.

[6] Wang Hongzhong, the relationship between supply and demand in the real estate market and the impact on the price of real estate, The Modern Management. 8(2007)111-131.

[7] Ma Zheng, from two aspects of supply and demand analysis of the reasons for the rise in real estate prices in China, The Commercial Economy. 9 (2008)55-67

[8] Gao Tiemei, econometric analysis and modeling of -EViews applications and examples, Tsinghua University Press, 2009

[9] Li Lianguang, Ge Xinfeng, A decision model based on two aspects of supply and demand, Journal of North Central University. 3 (2009)89-100.

[10] Liu Juan, from the relationship between supply and demand in the real estate market to talk about the long-term mechanism of regulation and control, Modern Economic Information. 15 (2010)97-102

[11] Luo Yongmin, the impact of urbanization on housing prices, linear or nonlinear, Based on the empirical analysis of four panel data regression models. The Financial Research, 2011 4(2011)187-191. 